\title{
Original Article Tokyo Station City: The railway station as urban place
}

\author{
John Zacharias ${ }^{\mathrm{a}, *}$, Tianxin Zhang ${ }^{\mathrm{b}}$ and Naoto Nakajima ${ }^{\mathrm{c}}$
}

a'Department of Geography, Planning and Environment, Concordia University, Montréal, Canada

H3G $1 \mathrm{M} 8$.

E-mail: zachar@alcor.concordia.ca

${ }^{\mathrm{b}}$ College of Urban and Environmental Sciences, Peking University, Beijing 100871 China.

E-mail: ztxpku@qq.com

${ }^{c}$ Faculty of Environment and Information Studies, Keio University, 5322 Endo, Fujisawa, Kanagawa

252-0882 Japan.

E-mail: naoto@sfc.keio.ac.jp

${ }^{*}$ Corresponding author.

\begin{abstract}
Railway stations in Japan and elsewhere are undergoing redevelopment to accommodate new spaces of consumption and leisure. Tokyo Station redevelopment is a representative case illustrating the experiment of integrating new facilities into an existing spatial system. The station's image is being recast as an important urban centre in Tokyo with a particular mix of prestige business, shopping and unique entertainment venues. The walking network is being reconfigured in a larger space with a complex set of new land uses, leading to new spatial configurations and patterns of behaviour. These transformations support a new role for the station. The station redevelopment, along with related investments in the surrounding space represent a distinctly Japanese approach to transit-oriented development. This article examines the urban design strategy underlying these transformations.
\end{abstract}

URBAN DESIGN International (2011) 16, 242-251. doi:10.1057/udi.2011.15

Keywords: train station; pedestrians; redevelopment; spatial behaviour

\section{Introduction}

Nowhere in the world can one find railway station complexes as large as in Japan. The railways themselves play a central role in urban transportation in Japanese cities, connecting suburb to centre, and city to city. The urbanization that Japan experienced in the twentieth century was accompanied by rapid development of the railway network within urban regions. At the same time, Japanese city centres were deeply affected by railway station development and redevelopment (Onishi, 1994).

Transit-oriented development (TOD) in Japan is a fundamental characteristic of all central city urban development, and is almost exclusively rail-based and specifically not intermodal. TOD refers to the land use characteristics of areas where transit is being promoted (Dittmar and Ohland, 2004; Lund et al, 2004). Higher density development and mixed land uses have been used in North America and elsewhere to promote public transit use. TODs in North America typically combine road-based transportation and one or more forms of public transit. After the Second World War, the railway became one of the most important tools for development in Japan, particularly in the context of a weak planning system (Sorensen, 2002). As a result of suburbanization with relatively undeveloped road infrastructure, commuting by train and subway became the most effective way to travel for most people who live in the suburbs and work in city centres. This urban spatial development created unprecedented demand for railway services, which were then met by the railway companies. In the late 1990s, the train line density was $1.01 \mathrm{~km}$ of line for every square kilometre with 86 per cent of all travel in Tokyo by rail. The comparable figures were respectively $0.74 \mathrm{~km} / \mathrm{km}^{2}$ 
and 65 per cent in London and Paris, and $0.41 \mathrm{~km} / \mathrm{km}^{2}$ and 61 per cent in New York (Focas, 1998). In spite of the large part of the travel market occupied by the railway and the intensity of the operations, the companies are involved in much more than rail operations. Since 2000, railway station redevelopment has become one of the most significant new urban regeneration programmes underway in major Japanese cities. The stations and adjacent railway properties are undergoing physical transformation to accommodate new urban functions and to enhance the passengers' travel experience. The surrounding neighbourhoods are also involved due to their multi-layered connection with the stations as well as their close proximity. Railway stations are consequently performing a different role in the city than that of transport hub, becoming cultural symbols, social communication hubs and business centres.

These projects parallel similar investment programmes in Europe, but with characteristics that are particular to Japan. The layouts, designs and activities of these redesigned stations reflect the operational structure of the railway companies, the location and physical condition of the stations, the close relationship with the surrounding urban space and building complexes, as well as the importance of rail-based travel in Japanese cities. Railway stations in Europe seldom attract high-end business and retailing activity although serious efforts are being taken to correct this historical problem (Bertolini and Spit, 1998). The trend in Japan is to combine commerce, leisure, media, fashion, information, as well as other advanced industries into a new 'city' within the city, so as to make the stations important spaces for creation and innovation. Such a focus on creative industry is hardly associated with TOD as practised in North America or Australia, for example. While continuing to serve the needs of travel within the city and beyond, the railway stations are becoming significant places in their own right and at or near the top of the hierarchy of such urban places.

The development of stations is in keeping with the TOD idea of attracting people from the nearby areas on foot. Major pedestrian facilities are then required to support the heavy flows of people through these local areas. In Japanese cities, as in European and North American examples, there is an immediately adjacent area which is in close relationship with the station. But uniquely in the Japanese case, the station building complexes are an accumulation of all kinds of functions, and not merely a point of distribution. Some private railway companies built station-based department store complexes before the Second World War. The Japan National Railways built many 'station department stores' after 1950. The pattern of new centres after 2000 is therefore in some continuity with earlier development practices, but at a higher level in quality, service and volume of clientele.

In recent years, the design and functions of the new underground station facilities in Japan are increasingly the object of research (for example, Tanimoto et al, 2004). Visitor preferences in facility design, lighting and social ambiance are receiving increasing attention. How people find their way and understand such underground spaces is also an important topic of investigation (Moriyama, 2009), for reasons of evacuation safety but also for the efficient functioning of commercial space. Scholars argue that rising rental rates and commercial benefits have encouraged projects to improve daily services for the white collar working population in the area (Yoshida, 2007). However, the special features of Japanese station redevelopments have not received enough attention. For example, there are few studies touching on the organizational mechanism underlying the redevelopment of railway stations. Nor is there enough attention given to the features of the Japanese approach to TOD, which has had such powerful effects on urban structure and has achieved very high ridership for rail-based travel. It is apparent that this country-wide investment programme is worthy of investigation in its own right because it is at an early stage of innovation and experimentation. What is learned from the Japanese case will also be of interest to planners working on railway station developments in Europe, China and North America.

In recognition of the above, this article examines one such railway station redevelopment project, Tokyo station, from the urban design perspective. Firstly, we discuss why the railway companies operating at Tokyo station are making these particular investment decisions. Secondly, the programmes themselves are examined for their contribution to the making of a new urban place in the constellation of such places in the Tokyo metropolitan region. Thirdly, how the spaces and their associated activities are accommodated within the physical constraints of the stations and the surrounding environment is considered. Finally, we evaluate the effects of station restructuring on surrounding urban space, with particular attention to a pre-existing shopping facility adjacent the station. 


\section{Redevelopment of Railway Stations in Japan}

A new phase of station redevelopment began in the 2000 decade, when railway companies themselves invested in their properties, together with financial partners. Major stations such as Tokyo, Yokohama, Nagoya and Fukuoka saw large-scale redevelopment. The projects included extensions to the pedestrian system, the provision of new commercial facilities and public leisure spaces, atmospheric effects, and high-rise office buildings.

The common goal of Japanese railway station redevelopment projects is to enhance the instation commercial function among many others, making the station a powerful magnet for visitors. These projects are mostly initiated by the station companies, who need to diversify their operations under the Japanese railway system organization and operations.

There are roughly three types of railway companies: Japan Railways Group, which was founded as a result of the privatization and breakup of the Japanese National Railway in 1987, private companies and city-owned companies. Each company operates one or several lines. Most of the stations are also operated by the railway companies, whose railway lines pass through the station. When several lines of different companies intersect at a certain station, they normally share the intersection space and related facilities. The station is consequently operated collaboratively by several companies. In most cases, one of the companies acts as the chief owner. In order to interconnect with each other, the companies have to work together to achieve a reasonable spatial distribution plan that allows efficient interchange between the various lines. This often makes the station space very complex.

Until the 1970s, the Japan National Railways company operated many rail routes all over the country. They began to face economic difficulties in the late 1960s and had accumulated large debts by the beginning of the 1980s. To help the companies achieve financial health, the government began privatizing the railways, dividing JR into six passenger transportation companies according to their geographic locations. The privatization accompanied a change in regulation which allowed the newly privatized railway companies, like JR East, the major owner-operator of Tokyo station, to accumulate profits through commercial activities in addition to pure transportation uses (Ieda et al, 2001). In exchange, railway companies became responsible for recovering capital investment through their operations and related investment decisions. Although rail-based travel in Japan, as a proportion of all travel, is the highest worldwide at about 36 per cent of all kilometers travelled, many observers consider the railway system in Japan to be underinvested. Railway companies hold territorial monopolies, which discourage them from making investments in railway services. To make such improvements in services, these private companies must either raise fares or derive benefits from other operations. Improving rail services has become increasingly difficult as the cost of providing infrastructure has risen very rapidly. Expected decline in passenger numbers, as a result of demographic decline, is an additional reason companies are reluctant to invest (Ieda et al, 2001). On the other hand, their territorial monopolies encourage the companies to invest in ancillary services, which are also highly profitable, and represent an increasing proportion of the railway companies' revenues (Kanemoto and Kiyono, 1995). These services enhance the travel experience, do not add to travel cost and exploit the lands under control of the railway companies.

In an early study of redevelopment of inner city areas in Japan, it was observed that the addition of a department store or shopping centre had a significant positive effect on land value. The great majority of such developments that resulted in increased numbers of shoppers in the last two decades were at railway station locations (Onishi, 1994). However, the investments in ancillary services at railway stations are not evenly distributed over stations. One of the reasons for uneven investment is the availability of lands for such development. Another important reason is that commuters making non-work-related stops are most likely to make those stops at the commuting terminal and at the work place zone (Nishii and Kondo, 1992). As a consequence, interchange stations with good accessibility in the railway network attract office development and related commercial and personal services. Among these interchange station areas, a limited number of stations with both good accessibility and connectivity between urban and regional transport infrastructure are developing as important places in the urban region. Examples in Tokyo include Tokyo, Shinjuku, Shibuya and Ueno stations. In the larger metropolitan region, new rail-based centres have sprung up in Yokohama, Chiba and Omiya. As a consequence, once-simple and direct 
daily travel patterns have become much more complex, multi-directional and multi-purpose.

The land development policies of the Japanese railway companies are not unique to Japan although they have particular characteristics that distinguish them from the parallel activities of the European railway companies. In France, for example, rail passengers were spending 22 per cent of their travel costs on products and services within the railway station in the late 1990s (Perrin, 1998). The investment policies of the French, Dutch and German railway companies emphasize services related to travel and the improvement of the ambience of the station. The European railway station is increasingly an important place in the city, a destination in its own right and a magnet for related investment (Reusser et al, 2008). Commercial space nevertheless remains highly oriented to travel, whereas in Japan the station hosts a comprehensive set of services and products, equivalent to city core shopping districts. The highly integrated development of real estate with railway services in the Japanese cases is in part due to structural differences in the railway companies. The French, Dutch and German railway companies have distinct and relatively autonomous real estate divisions (Priemus and Konings, 2001). The European practice has been to hive off real estate no longer required for the core transport operations of the railway companies. The real estate developments on former railway lands are urban districts in their own right, accessible to the railway station but primarily a component of the city fabric. Developments have been designed to revitalize station-adjacent areas that suffer from poor connections to the rest of the city and a negative image (Staudacher, 2001). In Japan, however, the railway lines are an integral component of the city fabric, as are the stations. As a consequence, the real estate operations are an increasingly important part of railway activity, within the stations, on lands owned by the railway companies and in the immediately adjacent urban space. In this respect, the redevelopment of stations is equivalent to city centre revitalization.

\section{Tokyo Station Redevelopment Projects}

\section{The status of Tokyo station in Japan}

The redevelopment of Tokyo station is among the most prominent projects in the national trend of redevelopment. It is particularly important due to the station's symbolic status, important location, and its role in Tokyo's transportation system. It has national and global status because of the important districts immediately adjacent the station. Regarded as the entrance to and the face of Tokyo, it is surrounded by such important areas as the Imperial palace, and the Ginza and Nihonbashi commercial areas (Figure 1). On the west side of the station, the Marunouchi entrance leads to the Imperial palace and the office area. On the east, the Yaesu entrance leads to the important office buildings of Yaesu area.

Tokyo Station is the busiest railway station in Japan in terms of the number of trains. The number of passengers entering the station daily reaches 380000, ranking fifth among stations where the East Japan Railway Company is an owner. In contrast, income earned by the company within its station premises reaches 260 million yen per day, which places Tokyo station first in terms of benefit, ahead of Shinjuku station, for example, which earns the company some 160 million yen per day (Yoshida, 2007). On the other hand, Shinjuku station has far higher transiting passenger volumes than Tokyo station so that more space in the station is actually devoted to movement. The goods and services that would otherwise invest the station are displaced to neighbouring sites.

\section{The operational system of Tokyo station and its vicinity}

Tokyo Station is primarily owned by East Japan Railway Company (JR Higashi Nihon or JREAST), the privatized company once part of Japan (National) Railways (JR). The Shinkansen highspeed railway through Tokyo Station, along with space above and below the tracks is owned and operated by the Central Japan Railway Company (JR Tokai).

The Marunouchi side of the station has long been Tokyo's most prestigious office district. From 2000, high-rise towers were added to the low-rise blocks with efforts to preserve the façades of many buildings, including several that predate the Second World War. To compensate for the higher density currently being practiced in Marunouchi, Tokyo Metropolitan Government required an extensive and generously dimensioned underground walking system that connects many of the renewed buildings to Tokyo 


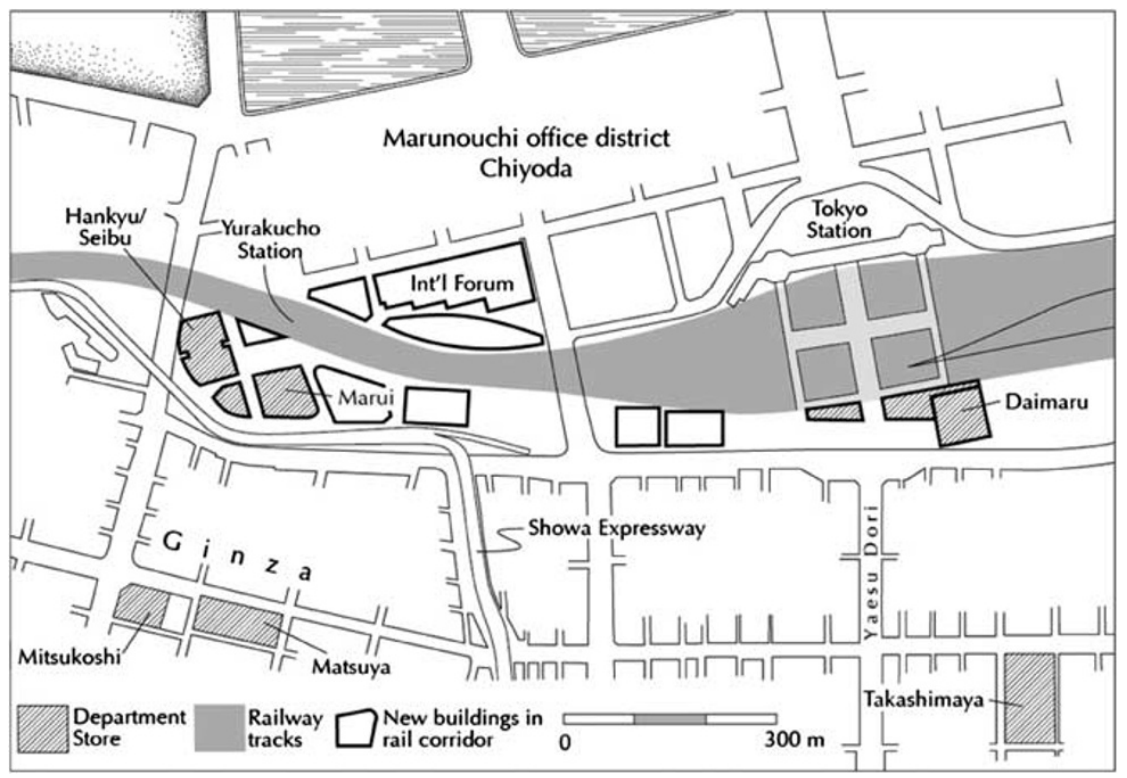

Figure 1: Tokyo Station in the local environment of central Tokyo with other recent developments along the railway corridor.

a

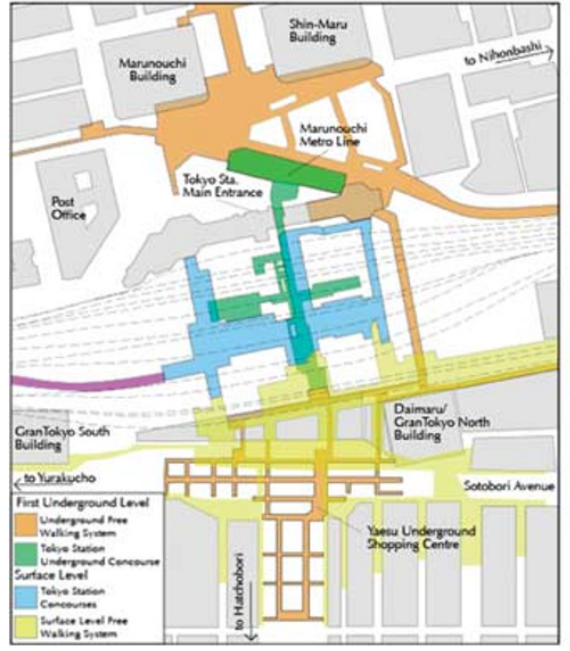

b

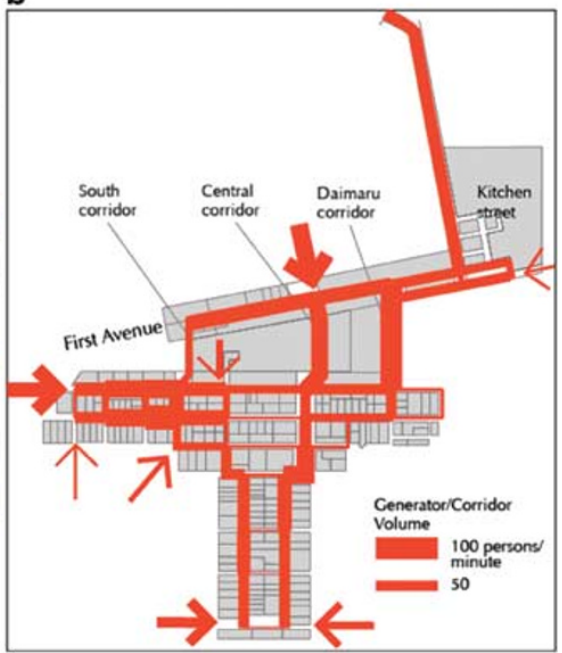

Figure 2: The pedestrian system of Tokyo Station (a) and the recorded pedestrian flows of First Avenue and Yaesu shopping centre $(\mathbf{b})$.

Station (Figure 2a). The major owner of real estate in Marunouchi is the Mitsubishi company whose headquarters is immediately opposite Tokyo Station entrance. This company's extensive real estate holdings facilitated the development of the underground system, since most of the underground corridors connect their own buildings under the streets. The building of the underground system provided the opportunity to redesign the street environment as well. Today the streets of Marunouchi are traffic-calmed and tree-lined, hosting sponsored public events, public art and luxury retailing.

On the east or Yaesu side of the station, major property owners include the Mitsui real estate company, the Kajima Yaesu development company, the International Tourism company and the Shinnihon Sekiyu (Nippon Oil Corporation, currently JX Nippon Oil and Energy Corporation). The Yaesu side has always been associated 
with everyday business, entertainment and living. The world-famous Ginza shopping district is within walking distance as is the Tsukiji wholesale fish market, the world's largest.

\section{The configuration of Tokyo station area}

Tokyo station is complex in configuration (Figure 2a). There are five platforms and 20 lines on the ground level; four platforms and eight lines underground serving urban railways; five platforms and 10 lines on the ground level for the Shinkansen; and finally, one platform and two lines for the subway lines. In addition, there are three station concourses and two layers of pedestrian system. There are three entrances from three main directions, namely Marunouchi at the west, Yaesu at the east, and Nihonbashi at the north-east, with the main pedestrian flow between the west and the east.

The ground level pedestrian system is at grade at its eastern, Yaesu entrance while elevated a few steps at the west exit, because of a slight declination toward the Imperial gardens and palace. The underground pathway system is entirely at the same level, immediately below the street and the three controlled station concourses. The underground level is linked to the ground with regularly spaced stairwells leading directly to uncovered sidewalks.

Despite the fact that the station offers one toll-free corridor that connects the east and the west, the huge volume and the complex space make Tokyo Station a major barrier between east and west, accentuating the different roles and character of Marunouchi and Yaesu. Bars and restaurants proliferate in the nearest reaches of Yaesu, supplying the Marunouchi business district which has little such activity of its own. As the railway companies begin to emphasize place-based activity and consumption, there is a new need to promote pedestrian linkage between the various components of the emerging underground system. Such underground facilities are exceedingly expensive to retrofit to existing station facilities, given the exiguity of the spaces and the abundance of complex underground infrastructure. It is important that the linkages work well and pedestrian flows are sufficient to support the costly commercial space created in this restructuring effort. The last section of this article examines one such linkage effort.

\section{Redevelopment projects at Tokyo station}

Considering the important status of Tokyo station in Japan and its role in the city, the key urban design challenge becomes firstly, to heighten the symbolic status of Tokyo station by emphasizing its unique identity; secondly, to make better links between the two sides of the station; thirdly, to make the station an integral part of the city.

There are two projects that show how Tokyo station responds to the above challenges. One is the Tokyo station city project for the whole station area, and the other is the First Avenue project for the underground pedestrian system.

\section{Tokyo Station City project}

As the main station company, JR East collaborated with other companies and launched a major reinvestment programme known as 'Tokyo Station City' (Figure 3). Its ambitious pursuit is to make Tokyo station a leading urban place in Tokyo. With this goal in mind, the redevelopment project has several components. The first is the restoration of the early twentieth-century station, damaged during the Second World War, to its original architectural form. This work accompanies the beautification project consisting of a tree-lined boulevard from the symmetrically arranged station through the Marunouchi district to the Imperial Palace. This vista is symbolically extended across the station to the Yaesu side by demolishing the Tetsudo Kaikan buildings on the Yaesu side, symbolically uniting the two sides of the station (Figure 4).

High-rise office buildings were constructed around station facilities at the Yaesu side and connected directly with station entrances. By transferring development rights to Yaesu side from the Marunouchi side, the historical station building could be restored in place while promoting new development on the other side of the station site. These new buildings include the Sapia tower, and GranTokyo North and South towers, all connected directly with the station's Marunouchi and Nihonbashi entrances through the GranRoof facility (Figure 5). The Sapia tower is owned by the station company, while the GranTokyo buildings are owned jointly by other companies. Tokyo Station City's office buildings are intended to be the most technically advanced in Japan. 'Sapia' derives from the Greek 'sapience', meaning knowledge or wisdom. More than merely a commercial venture, such buildings are intended to 


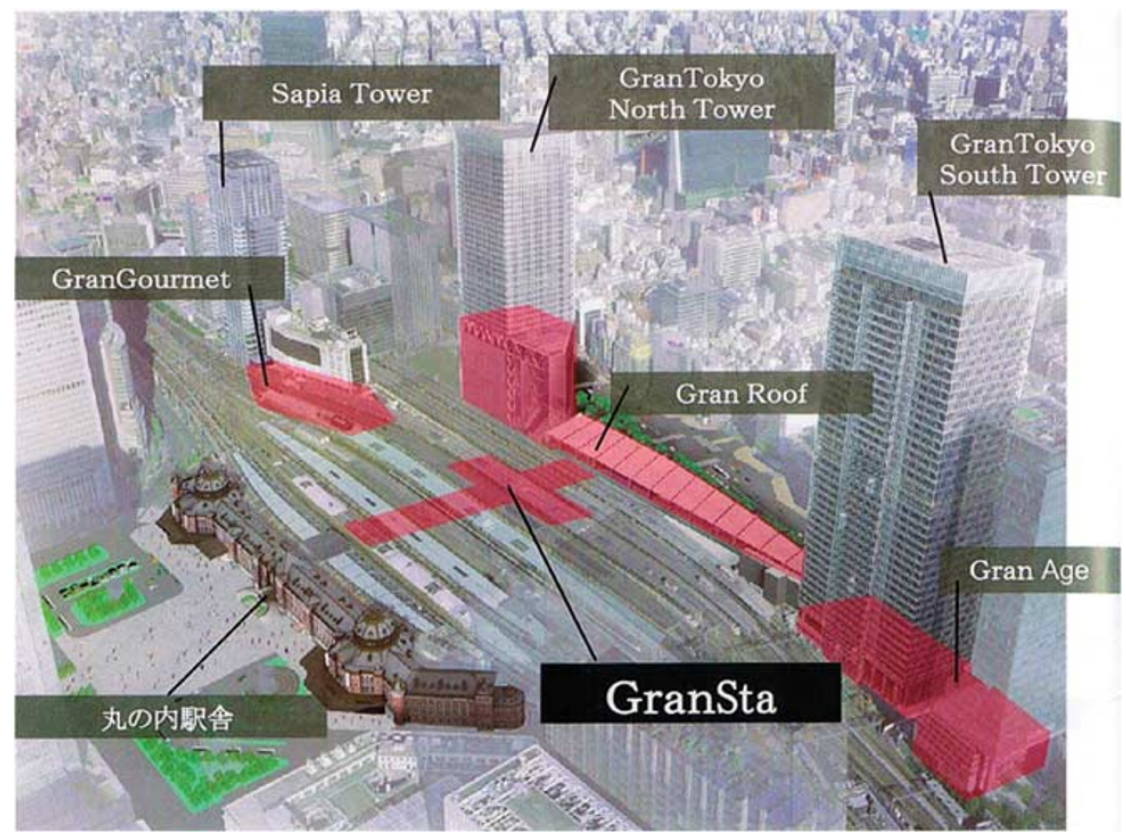

Figure 3: Tokyo Station City project as proposed by the developer.

Source: Gransta: Tokyo Station in Evolution and 'Tokyo Station City', Tetsudo Kaikan, 2009.

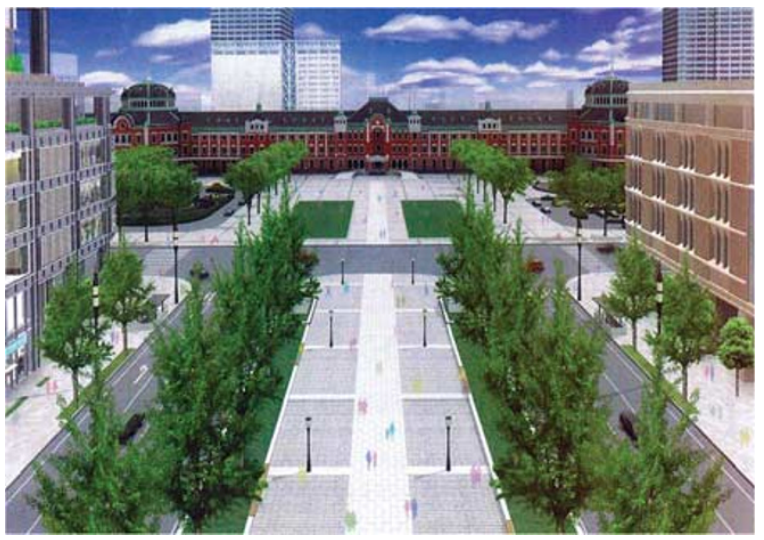

Figure 4: The proposed vista from the Imperial palace and gardens through Marunouchi to Yaesu, with the restored station façade.

Source: Gransta: Tokyo Station in Evolution and 'Tokyo Station City', Tetsudo Kaikan, 2009.

act as crucibles of research and education, with facilities devoted to university activities, for example. The GranSta facility opened in late 2007 and has become the main commercial space inside the station complex. A three-floor deck is under construction between the GranTokyo North and South towers, which will incorporate more shops and open spaces (Figure 5). The Station Square at the Yaesu side will be renewed by 2013. A great deal of design effort characterizes these

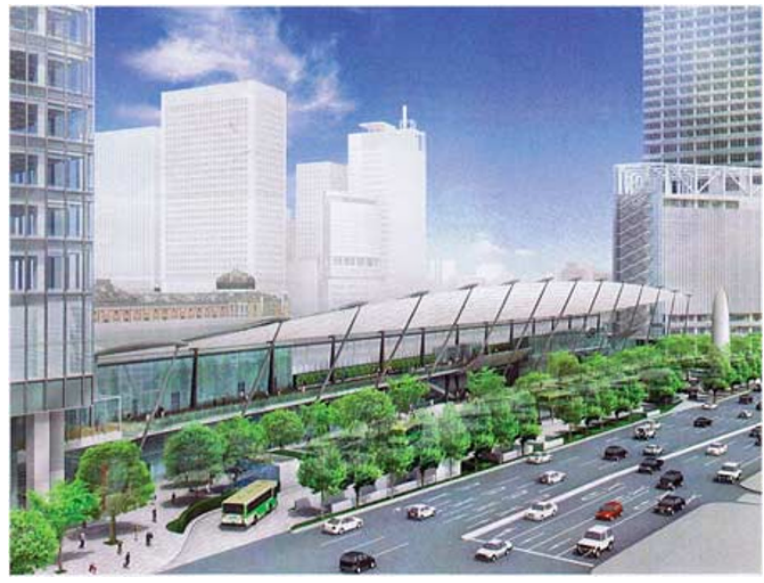

Figure 5: The Gran Roof facility connecting the recently completed towers at the Yaesu side of the station.

Source: Gransta: Tokyo Station in Evolution and 'Tokyo Station City', Tetsudo Kaikan, 2009.

projects, intended to give Tokyo station a preeminent position in the city and contribute to a favourable national and international image.

First Avenue project

Along with the large-scale Tokyo Station City project, there are also big changes in the pedestrian system. For example, Tokyo Station Development Company Limited, a subsidiary of station 
owner Central JR, opened the first phase of its commercial development known as First Avenue in 2008 (Figure 6a and b). First Avenue is located parallel to and two levels below the Shinkansen tracks at the underground level, directly connected to the north side passage between the Marunouchi and Yaesu sides of Tokyo station and at the same level as the long-open passage. It is also directly connected to the Yaesu Shopping Centre with one existing and two new connections. Kitchen Street, also developed by Tokyo Station Development Company, is directly connected to the sole pedestrian link between the Marunouchi and Yaesu sides of the station. The 'free' passage leads directly to Kitchen Street, First Avenue and the new Daimaru department store. First Avenue runs the length of the station with two new tunnels cut through to the Yaesu shopping centre, to facilitate linkage between
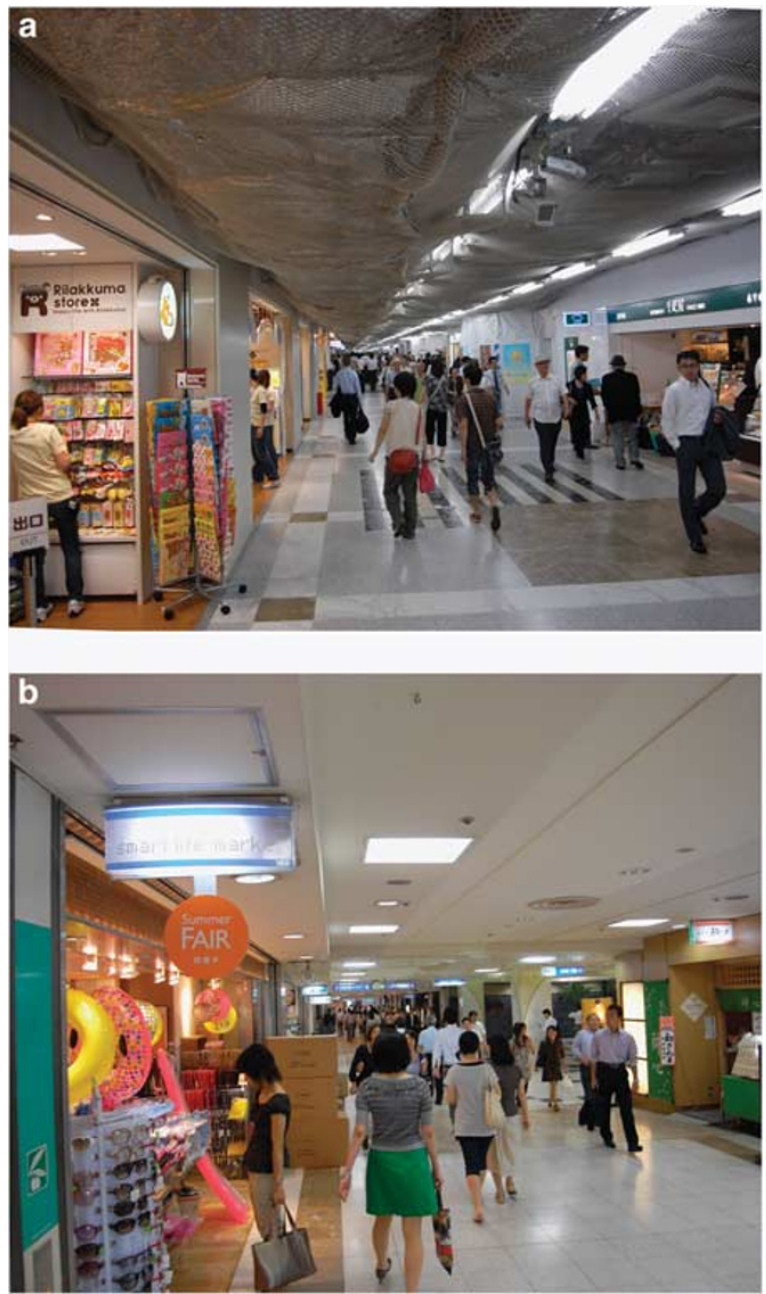

Figure 6: First Avenue phase 1 opened in 2008 (a); Phase 2 under development in 2009 (b).
First Avenue and the existing shopping centre although the two facilities are owned and operated by different companies. The First Avenue facility currently houses 102 shops, about onethird of which are devoted to food services. Two blocks of First Avenue are known as Tokyo Character Street, where 15 shops sell signature goods related to popular television shows. Another segment of this development, known as Tokyo Ramen Street, will fully open in 2011 and house eight famous noodle restaurants.

The case of First Avenue illustrates the placebased strategies of the railway station owners. The latest trends in products and services are finding their way into the stations, attracting a new clientele of younger people, countering the image of Tokyo Station as a somewhat staid, conservative business location. By specializing segments of the pedestrian walking system the companies have created a sense of place, even if place in this case is underground and connected to other places only with the pedestrian system.

The First Avenue project is a link between the existing pedestrian system and the Yaesu shopping centre. Although a place in its own right, attracting long lines of customers to the new restaurant venues, for example, it is also connected to the Yaesu shopping centre through the two new underground connections. Although under separate ownership, the companies have an interest in connecting with each other and benefitting from each other's trade. The pedestrian volumes recorded in 2009 in the First Avenue and Yaesu shopping centre show to what extent the visitors are shared among these different facilities (Figure $2 b$ ). The counts reveal strong flows between the facilities with inputs from the office buildings and from the Yaesu district, but also from the Marunouchi side.

Pedestrian volumes in this part of Tokyo station reach as high as 6000 persons per hour. High peak traffic is no longer restricted to mid day on working days, but is repeated in the late afternoon and early evening as visitors discover the Tokyo Station area as a place for consumption and educational activities. The success of the First Avenue project is leading a re-examination of the Yaesu shopping centre operation. That centre was positioned as a convenient service centre for business people in the vicinity and from the Marunouchi district, but also as a climate-controlled pathway into the station from the east. Traditionally, this centre paid much less attention to its place-based characteristics. The centre has a 
wide variety of affordable and readily available goods and services, mixed together in the various corridors. Until now, the operators have tried to identify the corridors thematically by colour and symbol, but not by the content of the operations or centre image. This approach seems likely to change as the visitors to Tokyo station gravitate to the newest venues. Already, the centre has begun to introduce new activities and design elements in the corridors nearest First Avenue in an attempt to capture more of the movement.

Overall, the various operators in Tokyo station compete and cooperate. Limited pedestrian access and the restrictions of building underground have forced the various property operators to consider how to use common facilities, including the pedestrian system, to their own advantage. While one of the greatest challenges of building in underground space is creating a viable and sustainable image in the long term, these experiments at Tokyo station illustrate one approach using activity themes concentrated at places with attention given to the connections between such places.

\section{Conclusion and Discussion}

Japanese station redevelopment projects show a distinctive approach to TOD, in which the central station complex becomes more multifunctional, and the linkage system is more thematic to satisfy a diversity of needs.

This change is made possible through close cooperation between the land owners. In the Tokyo station case, although JR East, Central JR and Mitsubishi are able to undertake their own redevelopment projects, the social and commercial success of the whole system depends to a considerable extent on cooperation among these companies. Cooperation includes the development of linkage between the various components of Tokyo Station, largely through the further development of the underground pedestrian system.

In these redevelopment projects, the stations are no longer taken as an exclusively transportation-oriented facility, but rather as integrated city space. They begin to represent the cutting edge of the city by including fashion trends and new ideas in an up-to-date physical setting. These developments are transforming the railway stations. From their beginnings as a pure transportation hub, the stations also became commercial operations designed to serve business travellers. These commercial operations expanded to serve a larger segment of the population, adding leisure facilities and reasons to remain in the space for longer periods. The station areas are evolving again into places for the exchange of ideas and the promotion of lifestyle, within a physical framework that incorporates innovations in building and space technology. The railway stations are in effect becoming nerve centres for the so-called 'intelligent' city, in which the transportation function plays a supportive role and no longer a central role. Such places have the particular advantage of being exposed to the highest volumes of foot traffic in the city.

To achieve these ends, all the new facilities and spaces are tightly interwoven within the pedestrian system. This makes for a richer pedestrian experience but also one where the whole space is highly accessible. Because of early attention to the connectivity between surrounding areas and the railway stations, achieved through pedestrian facilities on the surface, the station is assured a steady flow of inbound pedestrian traffic (Figure 7a and b). The indoor walkable 'city' is
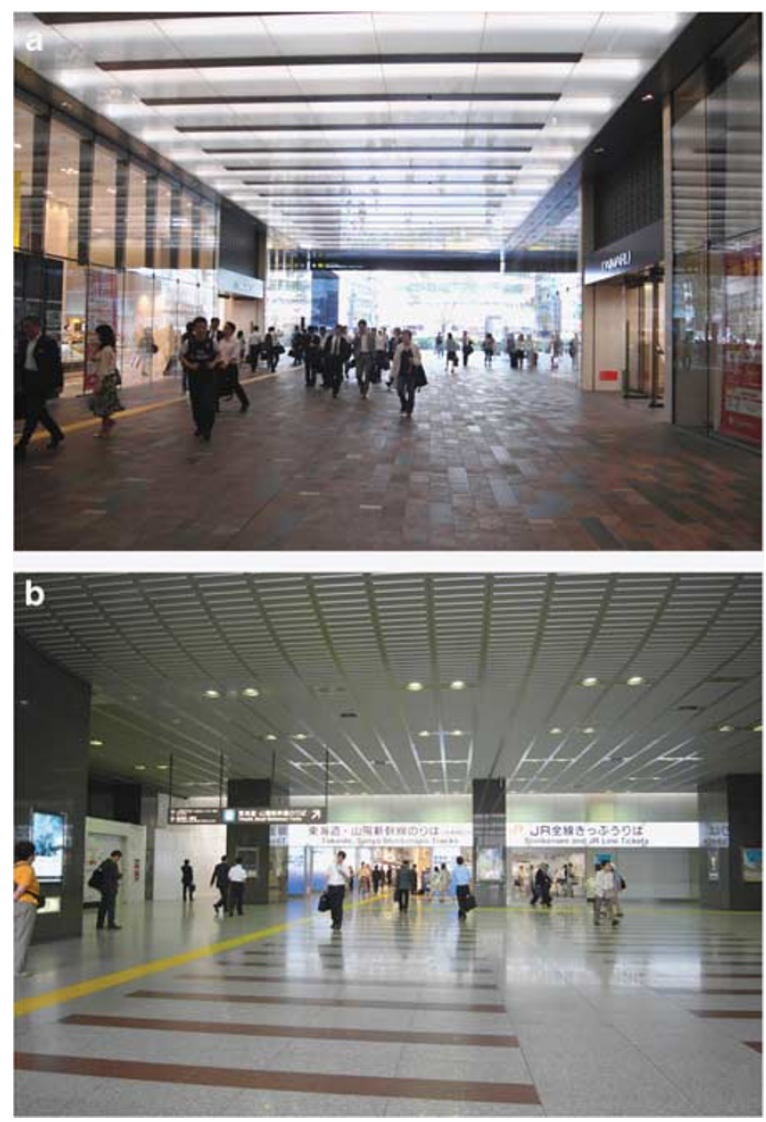

Figure 7: The Yaesu entrance and the new Daimaru department store (a); The Nihonbashi entrance to Tokyo station (b). 
thus connected to the larger space around the station, which is also undergoing transformation in keeping with the new and expanded role of the station itself.

Western countries can learn from this Japanese redevelopment process in a number of ways. A different organizational system makes the Japanese case difficult to copy directly. Nevertheless, Japanese railway stations show a highly efficient land use model, which makes maximum use of the space under, over and beside the stations. Strapped by limited land resources, the necessary concentration of facilities became one of the most positive features of the redevelopment. In this way, Japanese railway stations have avoided the experience of European railway stations where there persists a zone of lower value and less accessible space in the immediate vicinity of the station. In the European case, this persistent problem has delayed redevelopment of those inner city lands, even as the stations themselves have been upgraded. In the Japanese case, the station is enclosed by new developments and pedestrian facilities that have largely overcome the historical disconnect between the transportation facility and the surrounding environment.

The next phase of development is of particular interest. The evolution of the station as an important centre for creation and exchange provides an interesting template for the development of transportation hubs elsewhere. A place of transit becomes also a place for exchange and communication at the city's cutting edge.

\section{References}

Bertolini, L. and Spit, T. (1998) Cities on Rails: The Redevelopment of Railway Station Areas. London: E\&FN Spon.

Dittmar, H. and Ohland, G. (2004) The New Transit Town. Washington DC: Island Press.
Focas, C. in collaboration with the Institute of Public Administration (New York), Institut d'Aménagement et d'Urbanisme de la Région d'Ile-de-France, Tokyo Institute for Municipal Research (ed.) (1998) The Four World Cities Transport Study. London: Stationery Office.

Ieda, H., Kanayama, Y., Ota, M., Yamazaki, T. and Okamura, T. (2001) How can the quality of rail services in Tokyo be further improved? Transport Policy 8(2): 97-106.

Kanemoto, Y. and Kiyono, K. (1995) Regulation of commuter railways and spatial development. Regional Science and Urban Economics 25(4): 377-394.

Lund, H., Cervero, R. and Willson, R. (2004) Travel Characteristics of Transit-oriented Development in California, Final Report. California State Transportation Administration.

Moriyama, S. (2009) On-site experiment on group evacuation behaviour in large-scale underground shopping mall: Preference of pathway in passage crossing and cognition of exits. Journal of Environmental Engineering 74(637): 233-240, (in Japanese).

Nishii, K. and Kondo, K. (1992) Trip linkages of urban railway commuters under time-space constraints: Some empirical observations. Transportation Research B 26B(1): 33-44.

Onishi, Y. (1994) Urban commercial redevelopment in Japan and its evaluation. Journal of Retailing and Consumer Services 1(2): 107-112.

Perrin, P. (1998) Les commerces en gare-la valorisation commerciale. La revue générale des chemins de fer 4: 23-30.

Priemus, H. and Konings, R. (2001) Light rail in urban regions: What Dutch policymakers could learn from experiences in France, Germany and Japan. Transport Geography 9(3): 187-198.

Reusser, D., Loukopoulos, P., Stauffacher, M. and Scholz, R. (2008) Classifying railway stations for sustainable transitions - Balancing node and place functions. Journal of Transport Geography 16(3): 191-202.

Sorensen, A. (2002) The Making of Urban Japan. London: Routledge.

Staudacher, C. (2001) Bahnhof und Stadt-Bahnhofsviertel als Standort- und Lebensgemeinschaft. Wirtschaftsgeografische Studien 12(27-28): 17-36.

Tanimoto, M., Nakayama, C. and Sugiyama, N. (2004) A study of underground shopping malls from the viewpoint of their users: An investigation of Nagoya station and surrounding area. Journal of Nagoya Women's University 50: 93-100, (in Japanese).

Yoshida, H. (2007) On the development of Tokyo Station City, Ishizue. Japan Building Management Institute Bulletin 131: 3-7, (in Japanese). 